Western University

Scholarship@Western

Chemistry Publications

Chemistry Department

Fall 10-14-2015

\title{
An Azide-Functionalized Nitronyl Nitroxide Radical: Synthesis, Characterization and Staudinger-Bertozzi Ligation Reactivity
}

Stephanie M. Barbon

Pierangelo Gobbo

Wilson Luo

Jacquelyn T. Price

Mark C. Biesenger

See next page for additional authors

Follow this and additional works at: https://ir.lib.uwo.ca/chempub

Part of the Chemistry Commons

Citation of this paper:

Barbon, Stephanie M.; Gobbo, Pierangelo; Luo, Wilson; Price, Jacquelyn T.; Biesenger, Mark C.; Workentin, Mark S.; and Gilroy, Joe, "An Azide-Functionalized Nitronyl Nitroxide Radical: Synthesis, Characterization and Staudinger-Bertozzi Ligation Reactivity" (2015). Chemistry Publications. 70.

https://ir.lib.uwo.ca/chempub/70 
Authors

Stephanie M. Barbon, Pierangelo Gobbo, Wilson Luo, Jacquelyn T. Price, Mark C. Biesenger, Mark S. Workentin, and Joe Gilroy 


\section{An Azide-Functionalized Nitronyl Nitroxide Radical: Synthesis, Characterization and Staudinger-Bertozzi Ligation Reactivity}

\author{
Stephanie M. Barbon ${ }^{\text {at }}$ \\ Pierangelo Gobbo ${ }^{\text {at }}$ \\ Wilson Luo ${ }^{\mathrm{a}}$ \\ Jacquelyn T. Price ${ }^{\mathrm{a}}$ \\ Mark C. Biesinger ${ }^{b}$ \\ Mark S. Workentin*a \\ Joe B. Gilroy*a \\ ${ }^{a}$ Department of Chemistry and the Centre for Advanced \\ Materials and Biomaterials Research (CAMBR), The University \\ of Western Ontario, 1151 Richmond St. N., London, Ontario, \\ Canada, N6A $5 B 7$. \\ ${ }^{b}$ Surface Science Western, The University of Western Ontario, \\ 999 Collip Circle, London, Ontario, Canada, N6G 0J3. \\ ${ }^{\dagger}$ These authors contributed equally to this work. \\ mworkent@uwo.ca, joe.gilroy@uwo,ca
}

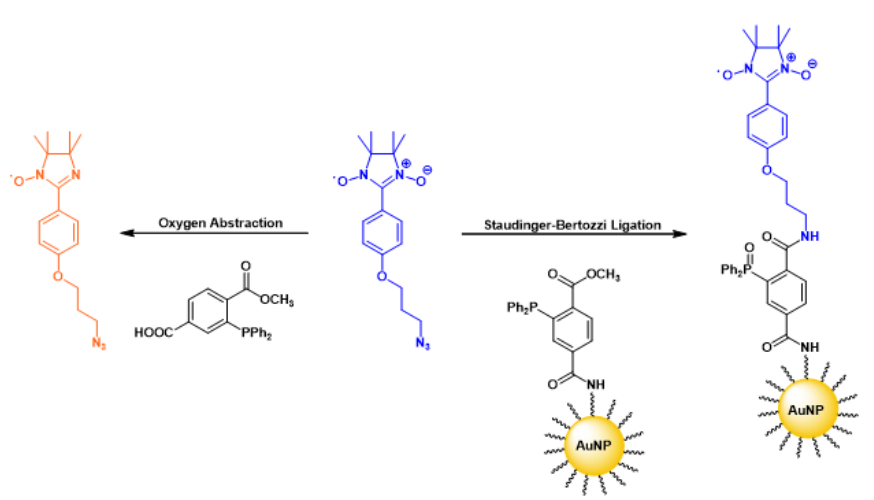

phenomenon is in nitroxide mediated polymerization, a common controlled radical polymerization reaction. ${ }^{11}$ These radicals are also used for spin labeling, which involves introducing radicals into biological systems or macromolecules and monitoring their location and local environment using electron paramagnetic resonance (EPR) spectroscopy, a noninvasive and non-destructive technique. These radicals specifically are favored due to their high stability in a variety of solvents and over a wide $\mathrm{pH}$ range, as well as their ability to be easily synthetically modified for a specific target. ${ }^{12}$ Decoration of nanoparticles and carbonaceous nanomaterials with stable radicals is also an area of significant interest. ${ }^{13}$

Due to the variety of applications of nitroxide and nitronyl nitroxide radicals, having a facile method for appending these radicals onto different materials (i.e., nanoparticles, polymers, biomolecules, etc.) is desirable. ${ }^{14}$ Herein, we report the synthesis of an azide-substituted nitronyl nitroxide radical, which benefits from resonance delocalization and is expected to have enhanced stability relative to similar azide-TEMPO radicals. ${ }^{15}$ Furthermore, as a proof of concept, we explore its interfacial reactivity through the Staudinger-Bertozzi ligation reaction.

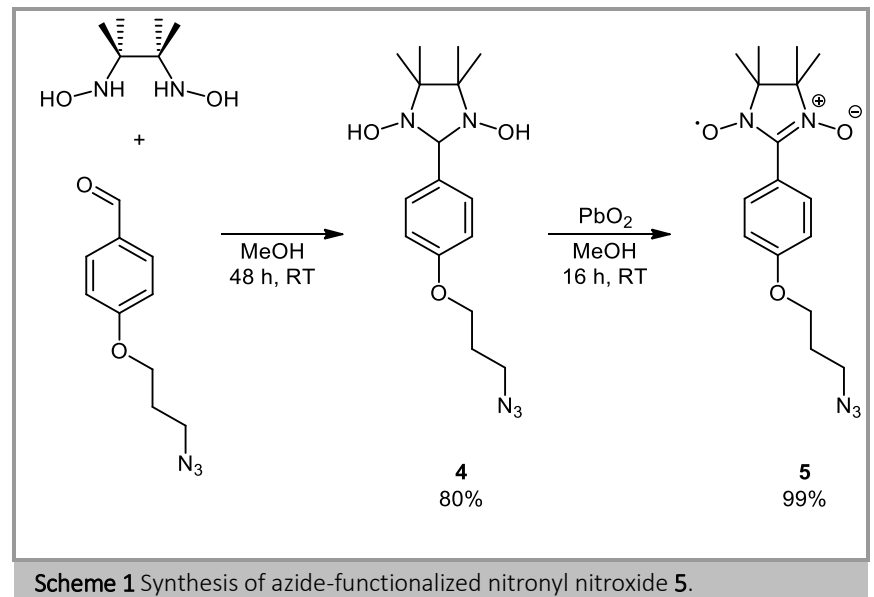

Nitronyl nitroxides and nitroxide radicals have been used for a variety of applications, including in organic synthesis for abstraction of hydrogen atoms and the oxidation of alcohols and sulfides. ${ }^{6}$ Another interesting application of the class of radicals is their use as radical scavenging agents. ${ }^{7}$ This trait has led to many applications including scavenging of protein based radicals, ${ }^{8}$ reactive oxygen and nitrogen species in the body ${ }^{9}$ and nitric oxide.10 One of the most common uses of this 
The 4-(3-azidopropoxy) substituted 1,3-dihydroxy-4,4,5,5tetramethyl-2-phenylimidazolidine $\mathbf{4}$ was synthesized from 4 (3-azidopropoxy)-benzaldehyde ${ }^{16}$ and 1,3-dihydroximidaoline ${ }^{17}$ and fully characterized by ${ }^{1} \mathrm{H}$ and ${ }^{13} \mathrm{C}$ NMR spectroscopy (Figures S1, S2), mass spectrometry and elemental analysis. ${ }^{18}$ Lead oxide was used to oxidize the imidazolidine $\mathbf{4}$ to the azidefunctionalized nitronyl nitroxide $\mathbf{5}$ (Scheme 1). To the best of our knowledge, $\mathbf{5}$ is the first example of an azide-functionalized nitronyl nitroxide.

The structure of radical $\mathbf{5}$ was confirmed by mass spectrometry, elemental analysis, electron paramagnetic resonance (EPR) spectroscopy and single crystal X-ray diffraction. The EPR spectrum of $\mathbf{5}$ showed an isotropic five-line signal (Figure 2), which is expected for a nitronyl nitroxide type radical, and matches well with the simulated spectrum (Figure S3). This confirms the presence of a radical in our sample, as well as proving the radical is delocalized over two identical nitrogen atoms.

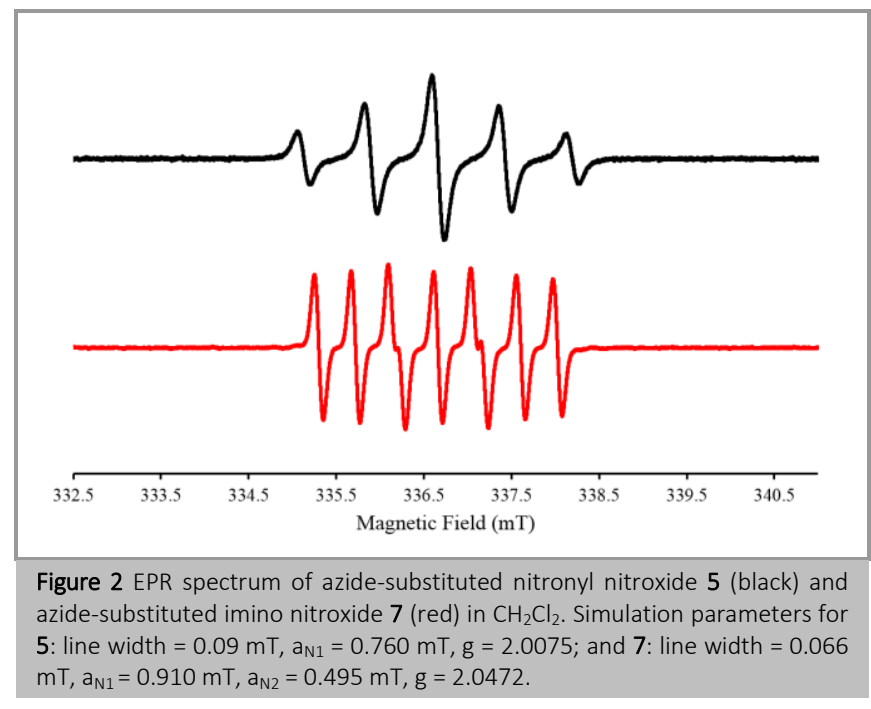

Single crystals suitable for X-ray diffraction studies were grown by cooling a concentrated pentane solution of 5. ${ }^{19}$ The solid-state structure confirms the expected connectivity (Figure 3). The C1-N1 and C1-N2 bond lengths are identical, and fall between the expected bond lengths for a $\mathrm{C}-\mathrm{N}$ single and double bond.20 Similarly, the N1-01 and N2-02 bonds are the same length, and shorter than a typical $\mathrm{N}-\mathrm{OH}$ bond (Table 1). This data confirms radical formation and delocalization.

To explore the reactivity of $\mathbf{5}$ in the Staudinger-Bertozzi ligation reaction, we reacted it with the model molecule methyl2-(diphenylphosphino)benzoate $\mathbf{6}$, which was synthesized according to a published method. ${ }^{21}$ The reaction was performed by stirring the components overnight in $\mathrm{CH}_{2} \mathrm{Cl}_{2}$ (Scheme 2). Interestingly, the major isolated product was orange rather than the expected dark blue colour of the azide-substituted nitronyl nitroxide radical 5. This orange solid, which was isolated in $84 \%$ yield, was identified by mass spectrometry as imino nitroxide 7 . The transformation from nitronyl nitroxides to imino nitroxides has been shown to be facilitated by triphenylphosphines, ${ }^{22}$ and results in the oxidation of triphenylphosphine to triphenylphosphine oxide (Scheme 2).
The EPR spectrum of the orange product was also consistent with the formation of an imino nitroxide radical, as the loss of symmetry in the molecule results in a seven-line signal (Figure S4), which is very different from the five line signal observed for nitronyl nitroxides (Figure 2). This experiment demonstrates that the reaction of nitronyl nitroxide $\mathbf{5}$ with the methyl-2(diphenylphosphino)benzoate $\mathbf{6}$ results mainly in the formation of imino nitroxide $\mathbf{7}$ in high yields.

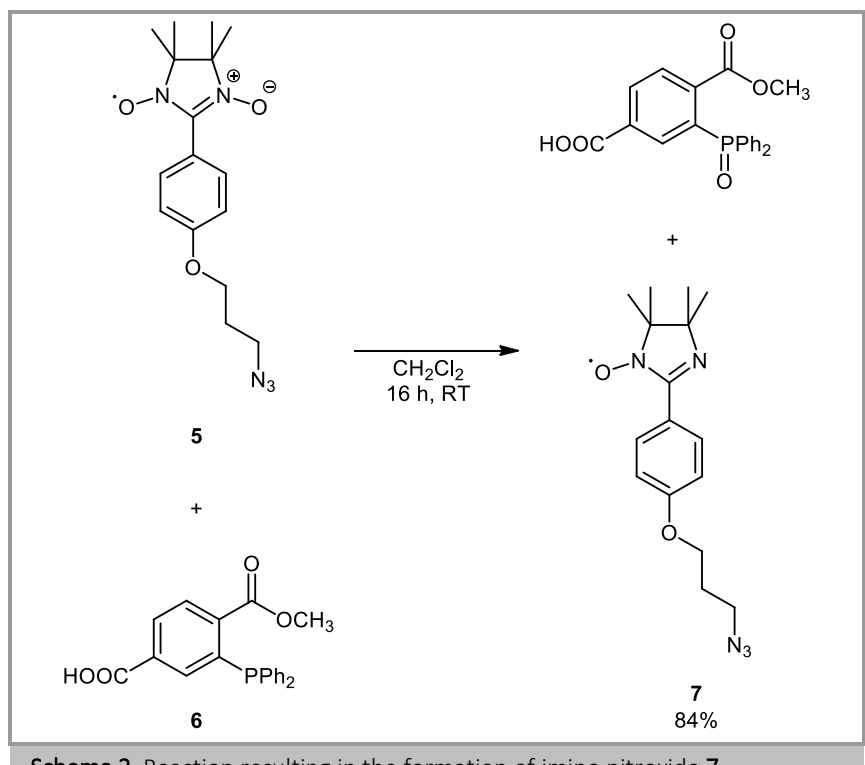

Scheme 2. Reaction resulting in the formation of imino nitroxide 7.

Interestingly, nitronyl nitroxide $\mathbf{5}$ showed different reactivity at the interface of gold nanoparticles. The azide-functionalized radical (ca. 200 equivalents) was reacted with nanoparticles displaying interfacial methyl-2-(diphenylphosphino)benzoate moieties (Staudinger-AuNP), which have been shown to react well with azide (bio)molecular systems. ${ }^{23}$ The Staudinger-AuNP contain $0.432 \mu \mathrm{mol}$ of methyl-2-(diphenylphosphino)benzoate moieties per milligram of nanoparticles. These AuNPs have an average nanoparticle raw formula of $\mathrm{Au}_{1500}\left(\mathrm{MeO}_{-}-\mathrm{EG}_{3}\right.$ S) ${ }_{500}\left(\mathrm{Ph}_{3} \mathrm{P}-\mathrm{EG}_{4}-\mathrm{S}\right)_{200}\left(\mathrm{Ph}_{3} \mathrm{P}=\mathrm{O}-\mathrm{EG}_{4}-\mathrm{S}\right)_{20}$, assuming that the AuNP are spherical and perfectly monodispersed in size (EG = $\left.-\mathrm{CH}_{2} \mathrm{CH}_{2} \mathrm{O}-\right)^{23}$

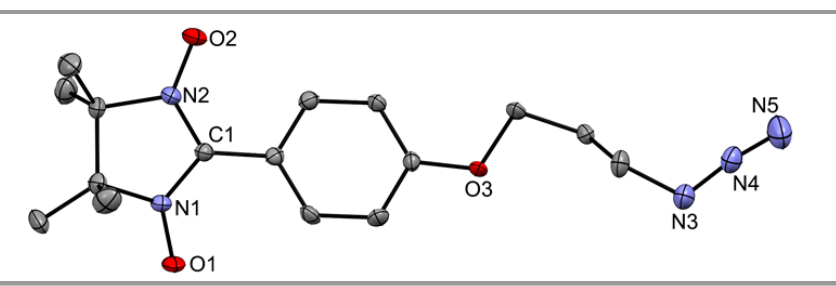

Figure 3 Solid-state structure of $\mathbf{5}$. Anisotropic displacement ellipsoids are shown at $50 \%$ probability and hydrogen atoms have been omitted for clarity.

Table 1 Selected bond lengths ( $\AA$ ) and angles (deg.) for nitronyl nitroxide 5

\begin{tabular}{ll}
\hline & 5 \\
\hline O1-N1, O2-N2 & $1.279(4), 1.281(4)$ \\
N1-C1, N2-C1 & $1.358(5), 1.351(5)$ \\
O1-N1-C1, O2-N2-C1 & $127.5(3), 126.1(3)$ \\
C2-N1-C1, C3-N2-C1 & $111.9(3), 111.8(3)$ \\
N1-C1-C8, N2-C1-C8 & $125.7(3), 126.4(4)$ \\
\hline
\end{tabular}


The reaction between the Staudinger-AuNP and azidesubstituted nitronyl nitroxide radical $\mathbf{5}$ was carried out by stirring in $\mathrm{CH}_{2} \mathrm{Cl}_{2}$ for $48 \mathrm{~h}$. Subsequently, the excess radical was removed by settling the nanoparticles through centrifugation (6000 rpm, $10 \mathrm{~min}$ ) and removing the mother liquor, using $\mathrm{CH}_{2} \mathrm{Cl}_{2}$ :hexanes 1:6 as the solvent. The particles, due to the presence of the interfacial stable organic radical, lost their solubility in polar organic solvents. The remaining traces of $\mathbf{5}$ were removed by making a film of AuNP inside a round bottom flask and the rinsing it with hexanes followed by $95 \%$ ethanol. The cleaning procedure was monitored by IR spectroscopy, by following the disappearance of the azide peak at $2100 \mathrm{~cm}^{-1}$ (Figure S5).

The purified radical-functionalized AuNP were first studied by transmission electron microscopy (TEM) in order to verify that the reaction with the radicals had not changed the size or shape of the nanoparticles. The TEM images of the starting material, before reaction with the radical, showed that Staudinger-AuNP $(3.63 \pm 1.4 \mathrm{~nm})$ self-assemble into islands. After the Staudinger-Bertozzi ligation with the azide-substituted nitronyl nitroxide radical, TEM images showed that the AuNPs retain the same size $(3.09 \pm 0.78 \mathrm{~nm})$ and shape (Figure 4$)$. The same images also showed that the nanoparticles were well dispersed after the interfacial reaction. The tendency of the Staudinger-AuNP to form self-assemblies that disassemble upon reaction with azides is consistent with a previous report. ${ }^{23}$

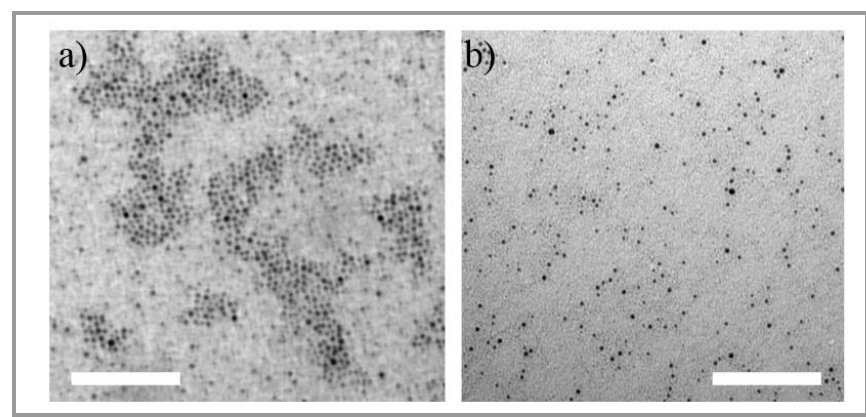

Figure 4 TEM images of a) Staudinger-Bertozzi ligation particles and b) radical-substituted gold nanoparticles. Scale bars $=100 \mathrm{~nm}$.

The EPR spectrum of the radical-functionalized AuNP showed a very similar pattern to that of the unreacted radical $\mathbf{5}$, a slightly anisotropic five-line signal (Figure 5), and is consistent with the simulated spectrum (Figure S6). The anisotropy is likely derived from the fact that the radicals are unable to tumble freely in solution when appended to the nanoparticle. This result verified that the nitronyl nitroxide radical remains intact throughout the interfacial reaction with the nanoparticles, and covalently attached imino nitroxide radicals are not present. This difference in reactivity from solution is likely due to the difference in steric hinderence between the molecular system and the nanoparticles. The methyl-2(diphenylphosphino)benzoate moieties appended to the nanoparticles are much more sterically hindered, and thus approach by the linear azide may be favored.

EPR spectroscopy was used to estimate the number of radicals present on the nanoparticles. By comparing the intensity of the EPR signal of the AuNP-radical sample, with the intensity of a standard (TEMPO) solution, the number of spins was estimated to be approximately $7.5 \times 10^{15}$ per milligram of sample (see supporting information for full details), which corresponds to $1.25 \times 10^{-2} \mu \mathrm{mol}$ of radical per milligram of sample.

The radical-functionalized AuNP were also characterized through X-ray photoelectron spectroscopy (XPS) and compared to that of the starting material Staudinger-AuNP (Figures S7). ${ }^{23}$ The high resolution scans of the $\mathrm{C} 1 \mathrm{~s}$ and of the $\mathrm{P} 2 \mathrm{p}$ corelines provide evidence of successful interfacial reactivity and allowed for an estimate of the amount of radical introduced onto the nanoparticle's surfaces. The $\mathrm{C} 1 \mathrm{~s}$ peak after interfacial Staudinger-Bertozzi ligation showed a significant decrease in the component at $289.30 \mathrm{eV}$ related to the carbonyl of the methyl ester functionality and a marked increase of the component at $288.00 \mathrm{eV}$ due to the newly formed amide bonds due to the newly formed amide bonds between the methyl-2(diphenylphosphino)benzoate and the azide-substituted nitronyl nitroxide radical. The P $2 p$ coreline showed a marked increase in the triphenylphosphine oxide component. From the integration of the active triphenylphosphine component at $131.65 \mathrm{eV}$ and the triphenylphosphine oxide component at $132.55 \mathrm{eV}$ we calculated formation of $31 \%$ oxidized triphenylphosphine, taking into consideration that there is $10 \%$ phosphine oxide in the starting AuNP. Assuming every moiety results from the interfacial Staudinger-Bertozzi ligation with the radical, this percentage would correspond to approximately $0.133 \mu \mathrm{mol}$ of radical per milligram of nanoparticles. This number is different than the value calculated by EPR. The additional phosphine oxide arises due to the competing reactivity of the nitronyl nitroxide radical $\mathbf{5}$ with the Staudinger AuNP, to yield imino nitroxide $\mathbf{7}$ in solution, which is removed via the washes. This explains the excess phosphine oxide observed through XPS. However, EPR spectroscopy confirmed unambiguously that the ligated radical is a nitronyl nitroxide.

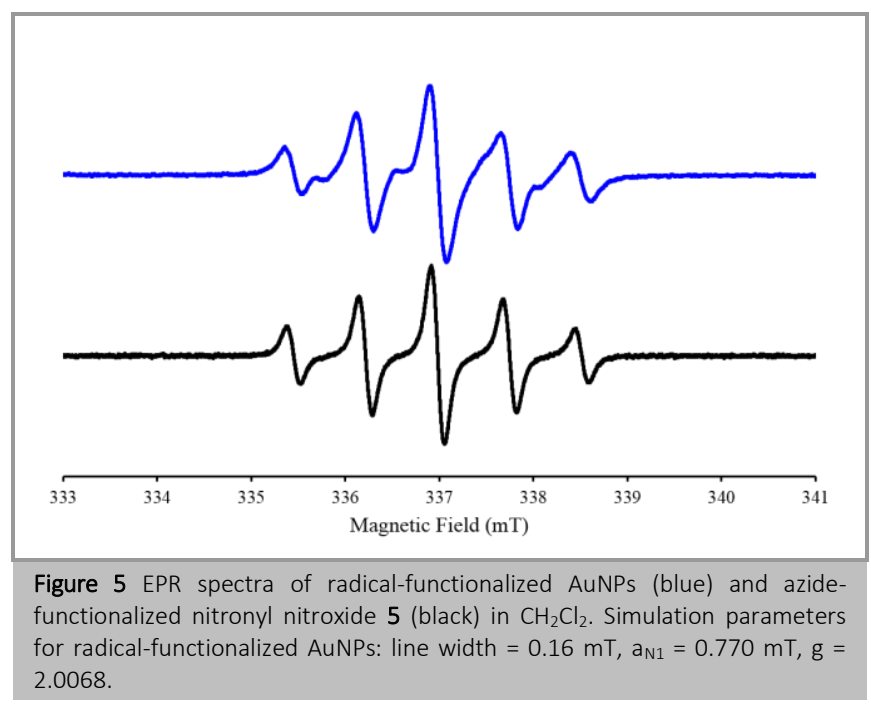

An important control experiment to verify the correct interfacial reactivity between Staudinger-AuNP and radical $\mathbf{5}$ and the absence of unspecific binding was also performed. For this experiment radical $\mathbf{5}$ was allowed to stir for $48 \mathrm{~h}$ in $\mathrm{CH}_{2} \mathrm{Cl}_{2}$ with triethylene glycol-monomethyl ether AuNP starting material (TEG-AuNP) that does not possess the interfacial methyl-2-(diphenylphosphino)benzoate moieties. Because of the absence of unspecific interaction between the radicals and 
the nanoparticles, the solubility properties of the TEG-AuNP did not change and therefore it was necessary to adopt a different cleaning procedure. The excess radical was removed by forming a AuNP film inside a round bottom flask from $\mathrm{CH}_{2} \mathrm{Cl}_{2}$, and washing with hexanes. Remaining traces of radical were removed by dissolving the TEG-AuNP in water and by filtering the insoluble radical through glass-wool. The successful removal of the azide-functionalized nitronyl nitroxide radical was monitored by IR spectroscopy as before (Figure S8). The EPR spectrum of the control experiment carried out using these nanoparticles (Figure S9) showed, as expected, no signal, and thus we can conclude that the azide-functionalized radical is reacting selectively with the triphenylphosphine moiety through the Staudinger-Bertozzi ligation, that there are no radicals bound to AuNP through any other bonding modes.

In conclusion, we have demonstrated the straightforward synthesis of the first azide-substituted nitronyl nitroxide radical. The reactivity of this radical was investigated towards modified triphenylphosphines for the Staudinger-Bertozzi ligation. The reactivity of the radical differed between the nanoparticle system (AuNP) and a small molecule model system. While in the model system, formation of an imino nitroxide was observed as the major product, we were able to observe the expected ligation product between the azide-functionalized nitronyl nitroxide and Staudinger-Bertozzi AuNP. The combination of EPR spectroscopy and XPS allowed us to demonstrate successful interfacial reactivity, and to estimate the number of nitronyl nitroxide radicals present in the nanoparticle sample. Furthermore, we believe that the approach described here can be easily transposed to other nanomaterials with potential application, for example, as solid-supported catalysts, contrasting agents, and spin-labels.

\section{Acknowledgment}

The authors thank the Natural Sciences and Engineering Research Council (NSERC) of Canada Discovery Grants (J. B. G. and M. S. W.), Canada Graduate Scholarships (S. M. B.), Vanier Graduate Scholarships (P. G.) and OGS (W. L.) programs, a Petro-Canada Young Innovator Award (J. B. G.) and The University of Western Ontario for financial support. We also thank Prof. Giovanni Fanchini for access to his EPR spectrometer.

\section{Supporting Information}

YES (this text will be updated with links prior to publication)

\section{References and Notes}

1. Gomberg, M., J. Am. Chem. Soc., 1900, 22, 757-771.

2. Stable Radicals: Fundamentals and Applied Aspects of OddElectron Compounds, Hicks, R. G., Ed; Wiley: West Sussex, 2010.

3. a) Rajca, A., Wongsriratanakul, J. and Rajca, S., Science, 2001, 294, 1503-1505; b) Winter, S. M., Hill, S. and Oakley, R. T., J. Am. Chem. Soc., 2015, 137, 3720-3730.

4. a) Rajca, A., Wang, Y., Boska, M., Paletta, J. T., Olankitwanit, A., Swanson, M. A., Mitchell, D. G., Eaton, S. S., Eaton, G. R. and Rajca, S., J. Am. Chem. Soc., 2012, 134, 15724-15727; b) Huang, L., Yan, C., Cui, D., Yan, Y., Liu, X., Lu, X., Tan, X., Lu, X., Xu, J., Xu, Y. and Liu, R., Macromol. Biosci., 2015, 15, 788-798. a) Nishide, H. and Oyaizu, K., Science, 2008, 319, 737-738; b) Janoschka, T., Hager, M. D. and Schubert, U. S., Adv. Mater., 2012, 24, 6397-6409.

6. a) Adam, W., Saha-Möller, C. R. and Ganeshpure, P. A., Chem. Rev., 2001, 101, 3499-3548; b) Vogler, T. and Studer, A., Synthesis, 2008, 1979-1993.

7. a) Samuni, A., Goldstein, S., Russo, A., Mitchell, J. B., Krishna, M. C. and Neta, P., J. Am. Chem. Soc., 2002, 124, 8719-8724; b) Damiani, E., Castagna, R., Astolfi, P. and Greci, L., Free Rad. Res., 2005, 39, 325-336.

8. a) Wright, P. J. and English, A. M., J. Am. Chem. Soc., 2003 , 125, 8655-8665; b) Lam, M. A., Pattison, D. I., Bottle, S. E., Keddie, D. J. and Davies, M. J., Chem. Res. Toxicol., 2008, 21, 2111-2119; c) Zhang, J., Zhao, M., Cui, G. and Peng, S., Bioorg. Med. Chem., 2008, 16, 4019-4028.

9. a) Krishna, M. C., DeGraff, W., Hankovszky, O. H., Sár, C. P., Kálai, T., Jekő, J., Russo, A., Mitchell, J. B. and Hideg, K., J. Med. Chem., 1998, 41, 3477-3492; b) Hoye, A. T., Davoren, J. E., Wipf, P., Fink, M. P. and Kagan, V. E., Acc. Chem. Res., 2008, 41, 87-97.

10. a) Konorev, E. A., Tarpey, M. M., Joseph, J., Baker, J. E. and Kalyanaraman, B., Free Radical Biol. Med., 1995, 18, 169-177; b) Rosen, G. M., Porasuphatana, S., Tsai, P., Ambulos, N. P., Galtsev, V. E., Ichikawa, K. and Halpern, H. J., Macromolecules, 2003, 36, 1021-1027.

11. a) Fischer, H., Chem. Rev., 2001, 101, 3581-3610; b) Hawker, C. J., Bosman, A. W. and Harth, E., Chem. Rev., 2001, 101, 3661-3688; c) Sciannamea, V., Jérôme, R. and Detrembleur, C., Chem. Rev., 2008, 108, 1104-1126.

12. Berliner, L. J. Spin Labeling: A Modern Perspective in Stable Radicals: Fundamentals and Applied Aspects of OddElectron Compounds; Hicks, R. G., Ed.; Wiley: West Sussex, 2010; pp 521-536.

13. a) Swiech, O., Hrynkiewicz-Sudnik, N., Palys, B., Kaim, A. and Bilewicz, R., J. Phys. Chem. C, 2011, 115, 7347-7354; b) Garbuio, L., Antonello, S., Guryanov, I., Li, Y., Ruzzi, M., Turro, N. J. and Maran, F., J. Am. Chem. Soc., 2012, 134, 10628-10637; c) Boccalon, M., Franchi, P., Lucarini, M., Delgado, J. J., Sousa, F., Stellacci, F., Zucca, I., Scotti, A., Spreafico, R., Pengo, P. and Pasquato, L., Chem. Commun., 2013, 49, 8794-8796; d) Swiech, O., Bilewicz, R. and Megiel, E., RSC Adv., 2013, 3, 5979-5986.

14. Krim, J., Taourirte, M., Grünewald, C., Krstic, I. and Engels, J. W., Synthesis, 2013, 45, 396-405.

15. a) Kálai, T., Hubbell, W. L. and Hideg, K., Synthesis, 2009, 1336-1340; b) Jakobsen, U., Shelke, S. A., Vogel, S., and Sigurdsson, S. T., J. Am. Chem. Soc., 2010, 132, 10424-10428.

16. Yilmaz, M. D., Bozdemir, O. A. and Akkaya, E. U., Org. Lett., 2006, 8, 2871-2873.

17. Shimono, S., Tamura, R., Ikuma, N., Takimoto, T., Kawame, N., Tamada, O., Sakai, N., Matsuura, H. and Yamauchi, J., J. Org. Chem., 2004, 69, 475-481.

18. Preparation of azide-functionalized nitronyl nitroxide 5: Imidazoline 4 (2.00 g, $5.96 \mathrm{mmol})$ and lead oxide ( $4.28 \mathrm{~g}, 17.9 \mathrm{mmol}$ ) were mixed in $50 \mathrm{~mL}$ methanol. A blue colour persisted almost immediately. The reaction was left to stir for $16 \mathrm{~h}$ before it was filtered and concentrated in vacuo to yield a dark blue residue. 
Nitronyl nitroxide $\mathbf{5}$ was purified by filtration through a small plug of neutral alumina with $\mathrm{CH}_{2} \mathrm{Cl}_{2}$ to yield a dark blue microcrystalline solid. Yield $=1.96 \mathrm{~g}, 99 \% . \mathrm{Mp}=$ 74-76 C. FT-IR (KBr): 3090 (m), 2992 (s), 2938 (s), 2881 (s), $2553(\mathrm{w}), 2096(\mathrm{~s}), 1606(\mathrm{~s}), 1572(\mathrm{~m}), 1531(\mathrm{~m})$ $\mathrm{cm}^{-1}$. UV-vis $\left(\mathrm{CH}_{2} \mathrm{Cl}_{2}\right): \lambda_{\max }=622 \mathrm{~nm}\left(\varepsilon=1,100 \mathrm{M}^{-1} \mathrm{~cm}^{-1}\right)$, $368 \mathrm{~nm}\left(\varepsilon=13,900 \mathrm{M}^{-1} \mathrm{~cm}^{-1}\right), 285 \mathrm{~nm}\left(\varepsilon=22,900 \mathrm{M}^{-1}\right.$ $\mathrm{cm}^{-1}$ ). Mass Spec. (EI, +ve mode): exact mass calculated for $\left[\mathrm{C}_{16} \mathrm{H}_{22} \mathrm{~N}_{5} \mathrm{O}_{3}\right]^{+}:$332.1723; exact mass found: 332.1721 ; difference: -0.45 ppm. Anal. Calcd. (\%) for $\mathrm{C}_{16} \mathrm{H}_{22} \mathrm{~N}_{5} \mathrm{O}_{3}$ : C, 57.82; H, 6.67; N, 21.07. Found: C, 58.09; H, 6.76; N, 21.01.

19. Crystallographic data for $\mathbf{5}$ has been deposited into the Cambridge Crystallographic Data Centre with the deposition number CCDC 1414896 and is also available in the primary data file associated with this manuscript.

20. CRC Handbook of Chemistry and Physics, Haynes, W. M., Ed., CRC Press, Boca Raton, Fla, 2012.

21. Wang, C. C.-Y., Seo, T. S., Li, Z., Ruparel, H. and Ju, J., Bioconjugate Chem., 2003, 14, 697-701.

22. Ullman, E. F., Call, L. and Osiecki, J. H., J. Org. Chem., 1970, 35, 3623-3631.

23. Gobbo, P., Luo, W., Cho, S. J., Wang, X., Biesinger, M. C., Hudson, R. H. E. and Workentin, M. S., Org. Biomol. Chem., 2015, 13, 4605-4612. 


\section{Supporting Information}

\section{An Azide-Functionalized Nitronyl Nitroxide}

\section{Radical: Synthesis, Characterization and}

\section{Staudinger-Bertozzi Ligation Reactivity}

Stephanie M. Barbon, ${ }^{a \dagger}$ Pierangelo Gobbo, ${ }^{a \dagger}$ Wilson Luo, ${ }^{a}$ Jacquelyn T. Price, ${ }^{a}$ Mark C. Biesinger, ${ }^{b}$ Mark S. Workentin, ${ }^{* a}$ Joe B. Gilroy $*^{a}$

${ }^{a}$ Department of Chemistry and the Centre for Advanced Materials and Biomaterials Research (CAMBR), The University of Western Ontario, 1151 Richmond St. N., London, Ontario, Canada, N6A 5B7. ${ }^{b}$ Surface Science Western, The University of Western Ontario, 999 Collip Circle, London, Ontario, Canada, N6G 0J3. Tel: +1-519-661-2111 ext. 86319 (MSW), 81561 (JBG); E-mail: mworkent@uwo.ca, joe.gilroy@uwo.ca ${ }^{\dagger}$ These authors contributed equally to this work.

\section{Table of Contents}

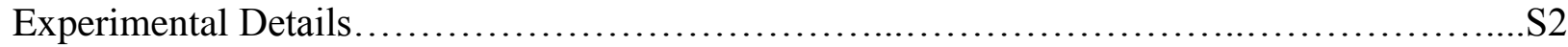

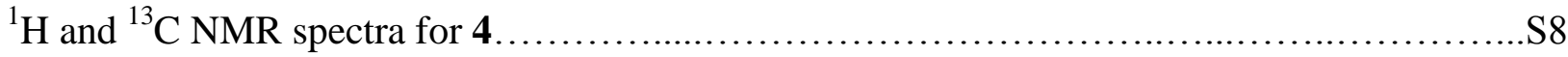

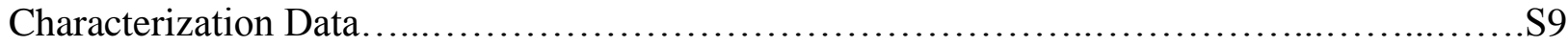

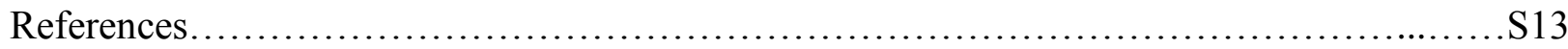




\section{Experimental - General considerations}

Solvents were obtained from Caledon Laboratories, dried using an Innovative Technologies Inc. solvent purification system, collected under vacuum, and stored under a nitrogen atmosphere over $4 \AA$ molecular sieves. 4-(3-azidopropoxy)-benzaldehyde, ${ }^{1}$ 1,3-dihydroximidaoline, ${ }^{2}$ Staudinger-AuNP, ${ }^{3}$ TEG-AuNP ${ }^{3}$ and methyl-2-(diphenylphosphino)benzoate $\mathbf{6}^{4}$ were prepared according to literature procedures. All other reagents were purchased from Sigma-Aldrich or Alfa Aesar and used as received. NMR Spectra were recorded on a $600 \mathrm{MHz}\left({ }^{1} \mathrm{H}: 599.5 \mathrm{MHz}\right.$, ${ }^{13} \mathrm{C}: 150.8 \mathrm{MHz}$ ) Varian INOVA instrument. ${ }^{1} \mathrm{H}$ NMR spectra were referenced to residual $\mathrm{CHCl}_{3}$ (7.27 ppm) and ${ }^{13} \mathrm{C}$ NMR spectra were referenced to $\mathrm{CDCl}_{3}(77.0 \mathrm{ppm})$. Mass spectrometry data were recorded in positive-ion mode using a high resolution Finnigan MAT 8200 spectrometer using electron impact ionization. UV-vis spectra were recorded using a Cary 300 Scan instrument. Four different concentrations were run for each sample and molar extinction coefficients were determined from the slope of a plot of absorbance against concentration. Infrared spectra were recorded on a $\mathrm{KBr}$ disk using a Bruker Vector 33 FT-IR spectrometer. Elemental analyses $(\mathrm{C}, \mathrm{H}, \mathrm{N})$ were carried out by Laboratoire d'Analyse Élémentaire de l’Université de Montréal, Montréal, QC, Canada.

Transmission electron microscopy (TEM) images were recorded from a TEM Philips CM10 microscope. The TEM grids (Formvar carbon film on 400 mesh copper grids) were purchased from Electron Microscopy Sciences and samples were prepared by dropcasting a drop of nanoparticle solution directly onto the grid surface. The drop was then carefully removed after $30 \mathrm{~s}$ with a soft tissue. XPS analyses were carried out with a Kratos Axis Ultra spectrometer using a monochromatic $\mathrm{Al} \mathrm{K}$ (alpha) source $(15 \mathrm{~mA}, 14 \mathrm{kV})$. The instrument work function was calibrated to give a binding energy (BE) of $83.96 \mathrm{eV}$ for the $\mathrm{Au} 4 \mathrm{f} 7 / 2$ line for metallic gold and 
the spectrometer dispersion was adjusted to give a $\mathrm{BE}$ of $932.62 \mathrm{eV}$ for the $\mathrm{Cu} 2 \mathrm{p} 3 / 2$ line of metallic copper. Specimens were mounted on a double sided adhesive tape and the Kratos charge neutralizer system was used on all specimens. Survey scan analyses were carried out with an analysis area of $300 \times 700$ microns and a pass energy of $160 \mathrm{eV}$. High resolution analyses were carried out with an analysis area of $300 \times 700 \mu \mathrm{m}$ and a pass energy of $20 \mathrm{eV}$. Spectra have been charge corrected to the main line of the carbon $1 \mathrm{~s}$ spectrum set to $285.0 \mathrm{eV}$ for aliphatic carbon (when needed). Spectra were analyzed using CasaXPS software (version 2.3.14).

\section{Electron Paramagnetic Resonance (EPR) Spectroscopy}

EPR measurements were made on ca. $10^{-6} \mathrm{M} \mathrm{CH}_{2} \mathrm{Cl}_{2}$ solutions of nitronyl nitroxide $\mathbf{5}$, functionalized and native Staudinger-AuNP and imino nitroxide 7 that had been subjected to three freeze-pump-thaw cycles in $0.4 \mathrm{~mm}$ quartz tubes using a JEOL JES-FA200 EPR. All measurements were made at $20{ }^{\circ} \mathrm{C}$ and $\mathrm{g}$ factors were referenced relative to a built-in manganese oxide marker within the resonance cavity of the instrument.

Quantification was done by comparing an EPR spectrum collected for a TEMPO solution of known concentration in toluene that was compared as outlined above. The integration of the TEMPO signal with respect to the manganese oxide marker was compared to that of the radicalfunctionalized Staudinger-AuNP sample. By assuming one molecule of TEMPO contributes one unpaired electron, the number of unpaired electrons present in the radical-functionalized Staudinger-AuNP sample could be determined.

\section{X-ray Crystallography Details}

A single crystal of nitronyl nitroxide $\mathbf{5}$ was mounted on a Mitegen polyimide micromount with a small amount of Paratone $\mathrm{N}$ oil. X-ray measurements were made on a Nonius diffractometer at a temperature of $150 \mathrm{~K}$. The data collection strategy included a number of $\omega$ and $\varphi$ scans which 
collected data over a range of angles, $2 \theta$. The frame integration was performed using SAINT. ${ }^{5}$ The resulting raw data was scaled and absorption corrected using a multi-scan averaging of symmetry equivalent data using TWINABS. ${ }^{6}$

The structures were solved by direct methods using the SIR 2011 program. $^{7}$ All nonhydrogen atoms were obtained from the initial solution. The hydrogen atoms were introduced at idealized positions and were allowed to ride on the parent atom. Twinning was present in the crystal and the twin domains were related by a $180^{\circ}$ rotation about [100]. The twin law used was:

$$
\begin{array}{rrr}
0 & 0 & 1 \\
0 & -1 & 0 \\
0 & 0 & -1
\end{array}
$$

and the twin fraction parameter refined to a value of $0.30670(172)$. The structural model was fit to the data using full matrix least-squares based on $F^{2}$. The calculated structure factors included corrections for anomalous dispersion from the usual tabulation. The structure was refined using the SHELXL-2014 program from SHELXTL. ${ }^{8}$ See Table S1 for additional crystallographic data. 
Table S1. X-ray diffraction data collection and refinement details for $\mathbf{5}$.

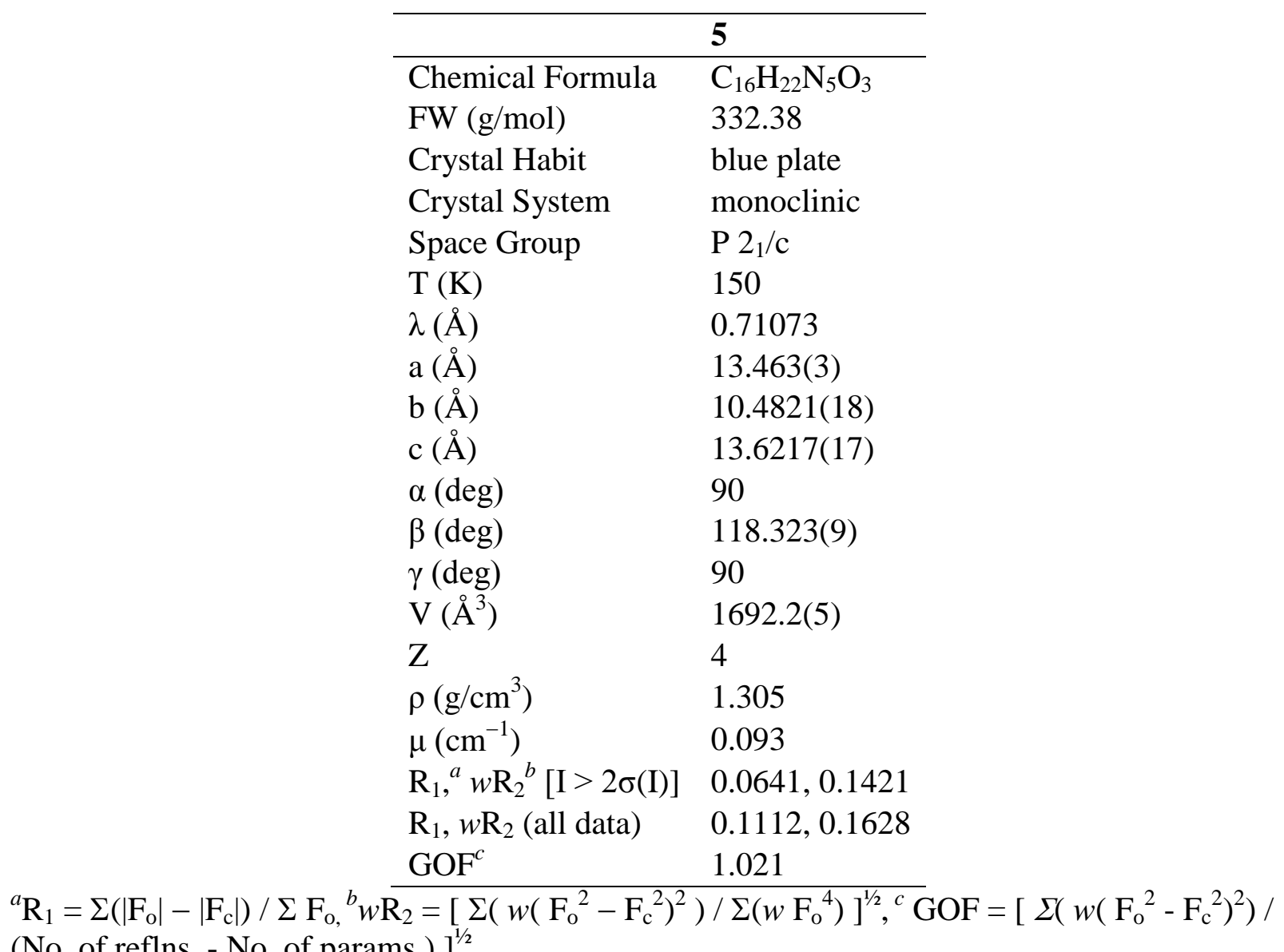

(No. of reflns. - No. of params.) $]^{1 / 2}$

\section{Experimental Procedures}

\section{Synthesis of 4-(3-azidopropoxy)-substituted 1,3-dihydroxy-4,4,5,5,-tetramethyl-2-phenyl- imidazolidine 4}

1,3-dihydroximidazolidine (0.47 g, $3.2 \mathrm{mmol})$ and 4-(3-azidopropoxy)-benzaldehyde (0.65 g, 3.2 mmol) were dissolved in $15 \mathrm{~mL}$ methanol and left to stir for $48 \mathrm{~h}$. The product was filtered off as a white powder. Yield $=0.85 \mathrm{~g}, 80 \% . \mathrm{Mp}=139-140{ }^{\circ} \mathrm{C} .{ }^{1} \mathrm{H} \mathrm{NMR}\left(599.5 \mathrm{MHz}, \mathrm{CDCl}_{3}\right) \delta 7.37$ $\left(\mathrm{d},{ }^{3} J_{\mathrm{HH}}=8 \mathrm{~Hz}, 2 \mathrm{H}\right.$, aryl $\left.\mathrm{CH}\right), 6.88\left(\mathrm{~d},{ }^{3} J_{\mathrm{HH}}=8 \mathrm{~Hz}, 2 \mathrm{H}, \operatorname{aryl} \mathrm{CH}\right), 5.36(\mathrm{~s}, 2 \mathrm{H}, \mathrm{OH}), 4.64(\mathrm{~s}, 1 \mathrm{H}$, $\mathrm{CH}), 4.06\left(\mathrm{t},{ }^{3} J_{\mathrm{HH}}=5 \mathrm{~Hz}, 2 \mathrm{H}, \mathrm{CH}_{2}\right), 3.52\left(\mathrm{t},{ }^{3} J_{\mathrm{HH}}=6 \mathrm{~Hz}, 2 \mathrm{H}, \mathrm{CH}_{2}\right), 2.06-2.04\left(\mathrm{~m}, 2 \mathrm{H}, \mathrm{CH}_{2}\right)$, $1.06\left(\mathrm{~s}, 6 \mathrm{H}, \mathrm{CH}_{3}\right), 1.01\left(\mathrm{~s}, 6 \mathrm{H}, \mathrm{CH}_{3}\right) .{ }^{13} \mathrm{C}\left\{{ }^{1} \mathrm{H}\right\} \mathrm{NMR}\left(100.6 \mathrm{MHz}, \mathrm{CDCl}_{3}\right): \delta 158.9,132.8,130.0$ 
114.5, 90.3, 67.1, 64.7, 48.4, 29.0, 24.3, 17.1. FT-IR (KBr): 3203 (br, s), 2976 (s), 2903 (s), 2875 (m), $2101(\mathrm{~s}), 1610(\mathrm{~m}), 1511(\mathrm{~m}), 1448(\mathrm{~m}), 1308(\mathrm{~s}), 1241(\mathrm{~s}) \mathrm{cm}^{-1}$. UV-vis $\left(\mathrm{CH}_{2} \mathrm{Cl}_{2}\right): \lambda_{\max }=$ $292 \mathrm{~nm}\left(\varepsilon=8,600 \mathrm{M}^{-1} \mathrm{~cm}^{-1}\right), 227 \mathrm{~nm}\left(\varepsilon=9,100 \mathrm{M}^{-1} \mathrm{~cm}^{-1}\right)$. Mass Spec. (EI, +ve mode): exact mass calculated for $\left[\mathrm{C}_{16} \mathrm{H}_{25} \mathrm{~N}_{5} \mathrm{O}_{3}\right]^{+}$: 335.1957; exact mass found: 335.1949 ; difference: -2.54 ppm. Anal. Calcd. (\%) for $\mathrm{C}_{16} \mathrm{H}_{25} \mathrm{~N}_{5} \mathrm{O}_{3}: \mathrm{C}, 57.30 ; \mathrm{H}, 7.51 ; \mathrm{N}, 20.88$. Found: $\mathrm{C}, 57.52 ; \mathrm{H}, 7.62 ; \mathrm{N}$, 20.70 .

\section{Synthesis of radical-functionalized Staudinger AuNP}

Staudinger-AuNP (0.143 g) and azide-substituted nitronyl nitroxide 5 (4.095 g, $12.32 \mathrm{mmol})$ were dissolved in $\mathrm{CH}_{2} \mathrm{Cl}_{2}(25 \mathrm{~mL})$. The mixture was stirred at room temperature for $48 \mathrm{~h}$. Subsequently, the excess azide radical was removed by centrifugation (6000 rpm, $10 \mathrm{~min}$ ), where the particles were allowed to settle and then could be removed using $\mathrm{CH}_{2} \mathrm{Cl}_{2}$ :hexanes 1:6 as solvent. The last remaining traces of radical were removed by making a film of AuNP from $\mathrm{CH}_{2} \mathrm{Cl}_{2}$ inside a round bottom flask and rinsing it with hexanes followed by $95 \%$ ethanol. The cleaning procedure was monitored by IR spectroscopy, by following the disappearance of the azide peak at $2100 \mathrm{~cm}^{-1}$.

\section{Control Experiment}

TEG-AuNP $(0.037 \mathrm{~g})$ and azide-substituted nitronyl nitroxide $5(0.037 \mathrm{~g}, 0.110 \mathrm{mmol})$ were dissolved in $20 \mathrm{~mL} \mathrm{CH}_{2} \mathrm{Cl}_{2}$. The mixture was stirred at room temperature for $48 \mathrm{~h}$. Subsequently, the excess radical was removed by making a film of AuNP from $\mathrm{CH}_{2} \mathrm{Cl}_{2}$ inside a round bottom flask and rinsing with hexanes. Remaining traces of radical were removed by dissolving the TEG-AuNP in water and by filtering the insoluble radical through glass wool. The cleaning procedure was monitored by IR spectroscopy, by following the disappearance of the azide peak at $c a .2100 \mathrm{~cm}^{-1}$. 


\section{Model Reaction - Synthesis of Imino Nitroxide 7}

Methyl-2-(diphenylphosphino)benzoate $6(0.500 \mathrm{~g}, 1.37 \mathrm{mmol})$ and azide-functionalized nitronyl nitroxide $5(0.501 \mathrm{~g}, 1.51 \mathrm{mmol})$ were dissolved in $30 \mathrm{~mL} \mathrm{CH}_{2} \mathrm{Cl}_{2}$ and stirred at $20{ }^{\circ} \mathrm{C}$ for $18 \mathrm{~h}$. The solvent was removed in vacuo and the resulting red solid was purified by column chromatography (1:1 EtOAc:hexanes, silica) to yield imino nitroxide 7 as a microcrystalline orange solid. Yield $=0.400 \mathrm{~g}, 84 \% . \mathrm{Mp}=32-34{ }^{\circ} \mathrm{C}$. FT-IR (KBr): $2975(\mathrm{~m}), 2923$ (m), 2869 (w), 2095 (s), 1607 (s), 1504 (s), 1468 (m), 1367 (m), 1302 (m), 1248 (s), 1176 (s) cm ${ }^{-1}$. UV-vis $\left(\mathrm{CH}_{2} \mathrm{Cl}_{2}\right): \lambda_{\max }=461 \mathrm{~nm}\left(\varepsilon=700 \mathrm{M}^{-1} \mathrm{~cm}^{-1}\right), 252 \mathrm{~nm}\left(\varepsilon=25,500 \mathrm{M}^{-1} \mathrm{~cm}^{-1}\right)$. Mass Spec. $(\mathrm{EI},+\mathrm{ve}$ mode): exact mass calculated for $\left[\mathrm{C}_{16} \mathrm{H}_{22} \mathrm{~N}_{5} \mathrm{O}_{2} \cdot \mathrm{H}\right]^{+}: 317.1852$; exact mass found: 317.1845 ; difference: -2.24 ppm. Anal. Calcd. (\%) for $\mathrm{C}_{16} \mathrm{H}_{22} \mathrm{~N}_{5} \mathrm{O}_{2}$ : C, 60.74; H, 7.01; N, 22.14. Found: C, 60.24; H, 7.08; N, 19.98 . 


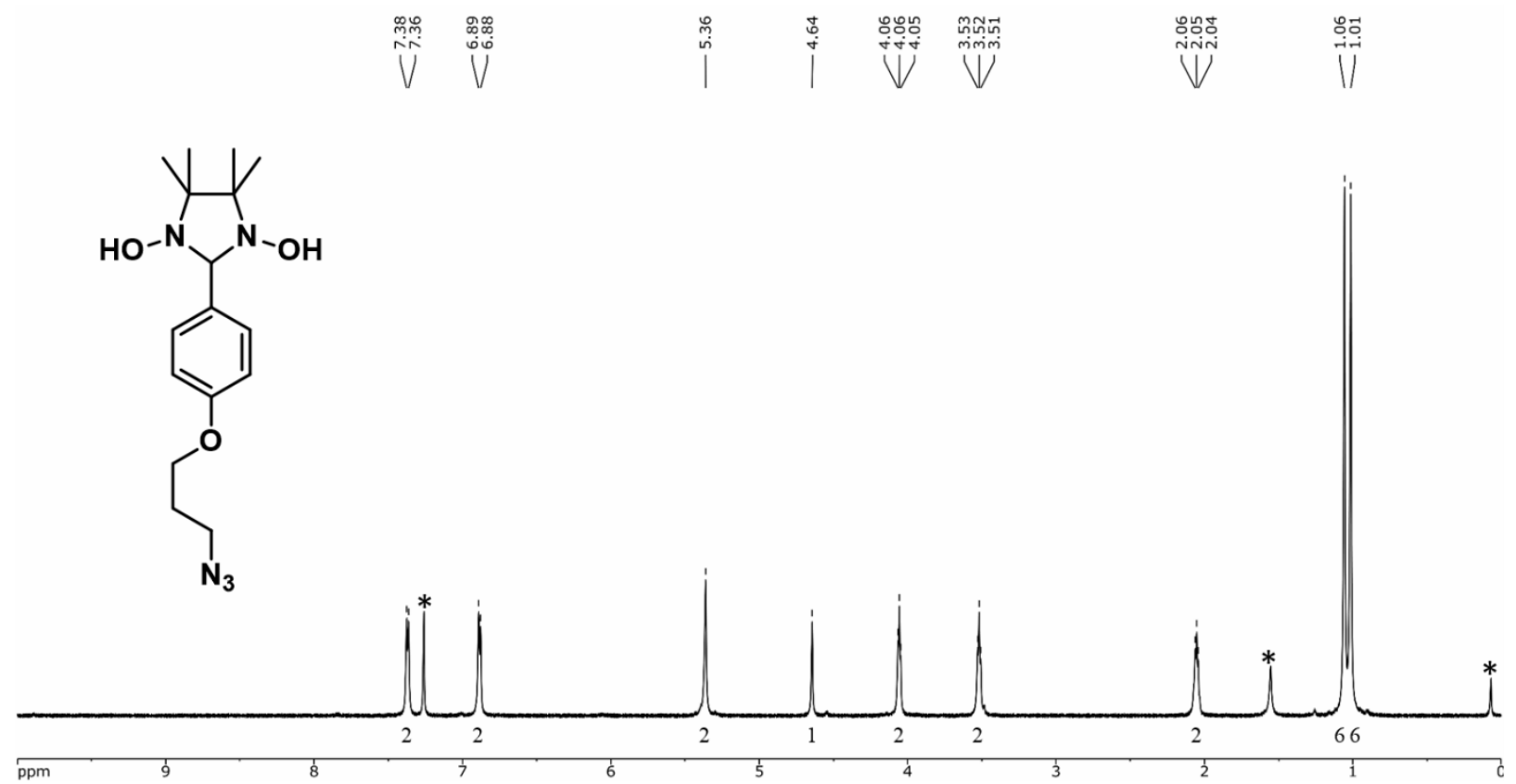

Figure S1. ${ }^{1} \mathrm{H}$ NMR spectrum of 4 in $\mathrm{CDCl}_{3}$. The asterisks denote residual solvent/grease signals.

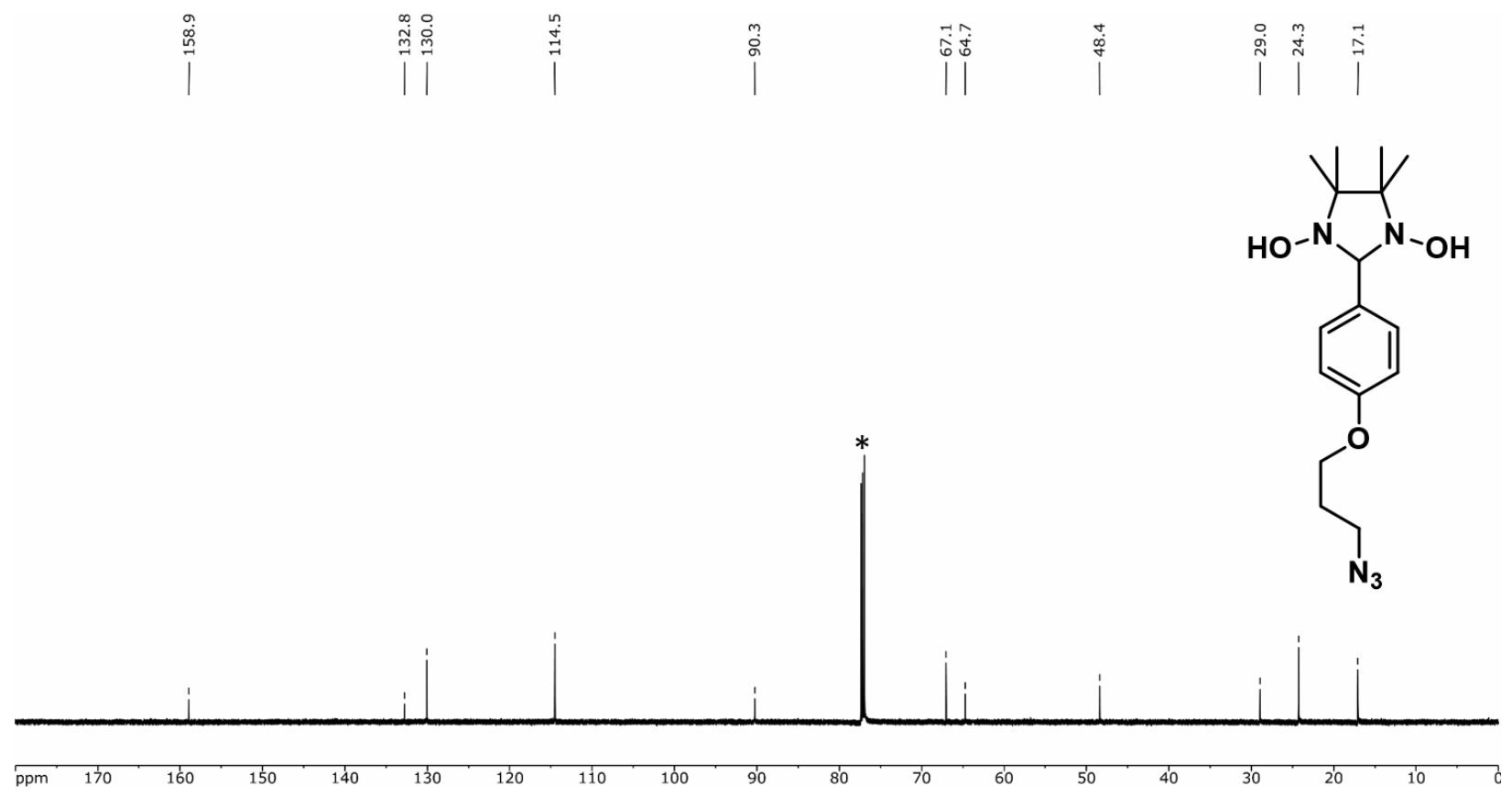

Figure S2. ${ }^{13} \mathrm{C}\left\{{ }^{1} \mathrm{H}\right\}$ NMR spectrum of 4 in $\mathrm{CDCl}_{3}$. The asterisk denotes solvent signal. 

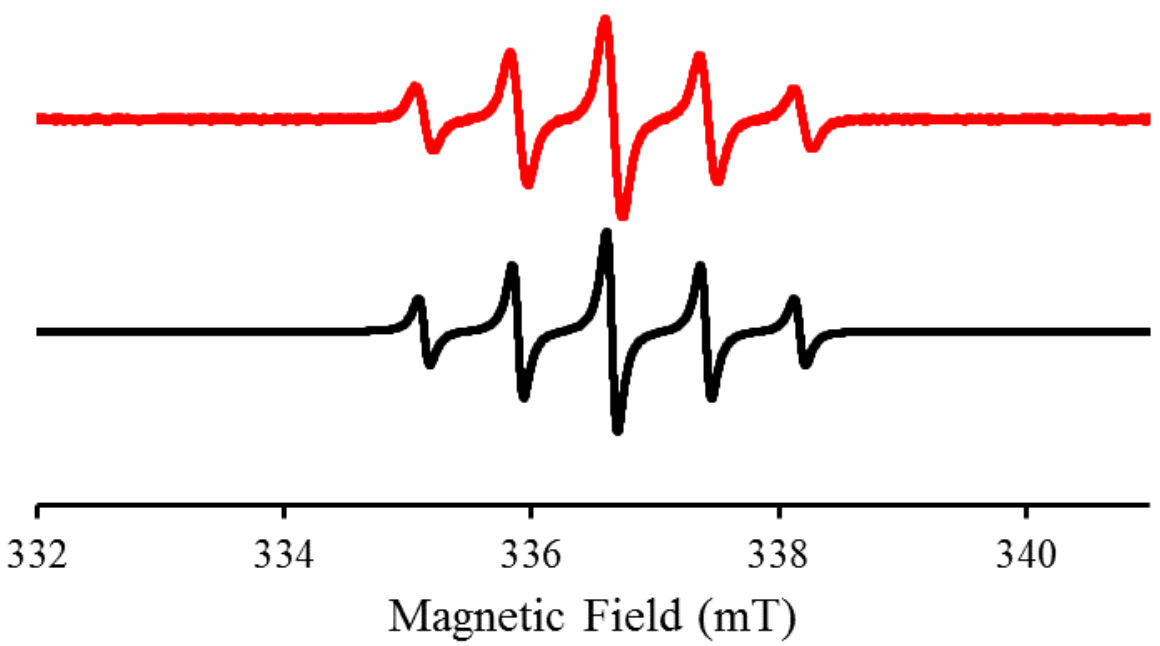

Figure S3. EPR spectrum (red) and simulated EPR spectrum (black) of azide substituted nitronyl nitroxide 5. Parameters used for simulation: line width $=0.09 \mathrm{mT}, \mathrm{a}_{\mathrm{N} 1}=0.760 \mathrm{mT}$, and $\mathrm{g}=$ 2.0075 .

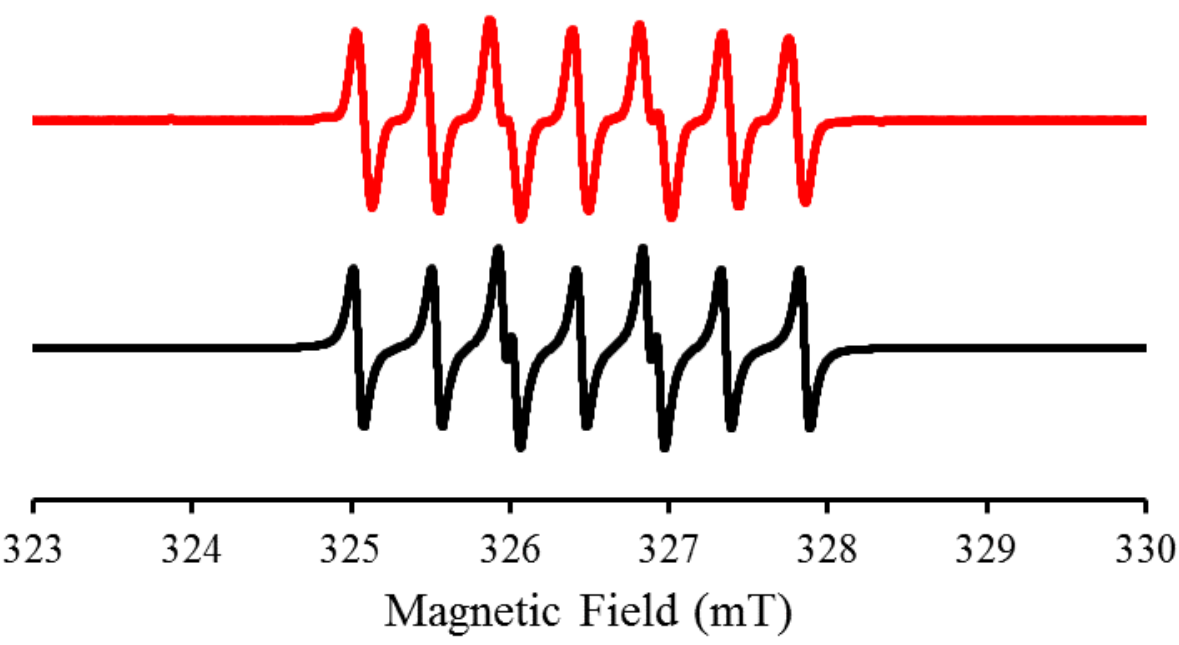

Figure S4. EPR spectrum (red) and simulated EPR spectrum (black) of imino nitroxide 7. Parameters used for simulation: line width $=0.066 \mathrm{mT}, \mathrm{a}_{\mathrm{N} 1}=0.910 \mathrm{mT}, \mathrm{a}_{\mathrm{N} 2}=0.495 \mathrm{mT}$, and $\mathrm{g}=$ 2.0472 . 

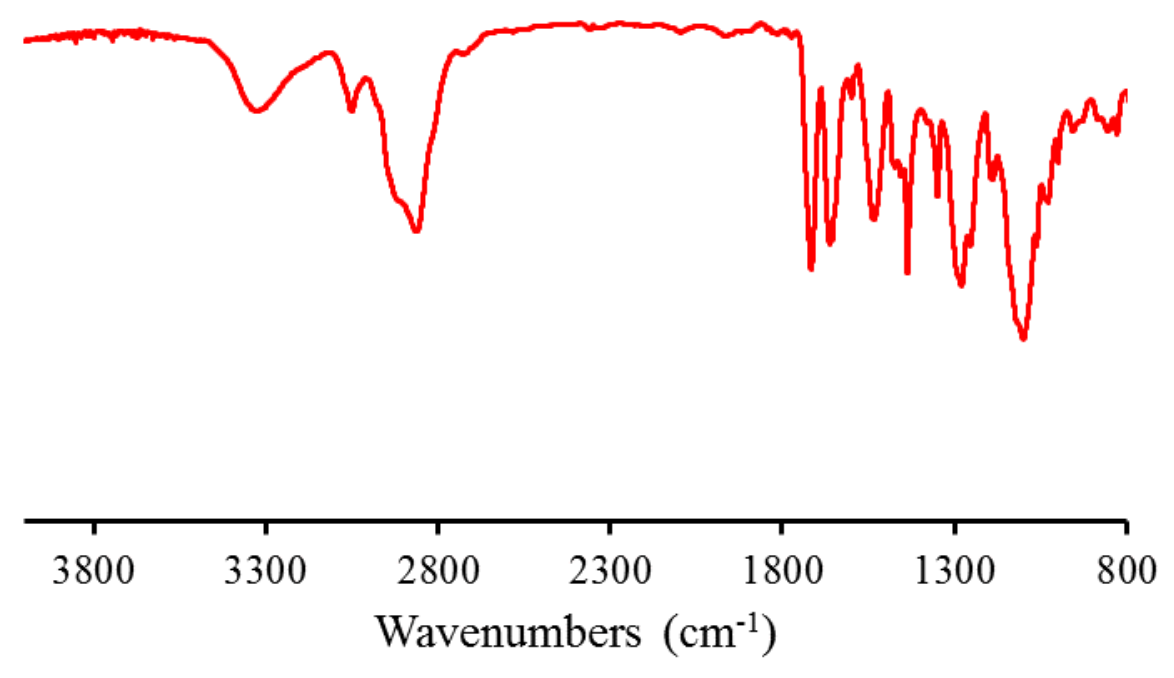

Figure S5. IR spectrum of radical functionalized AuNP after washing procedure recorded as a film on $\mathrm{KBr}$ disk.

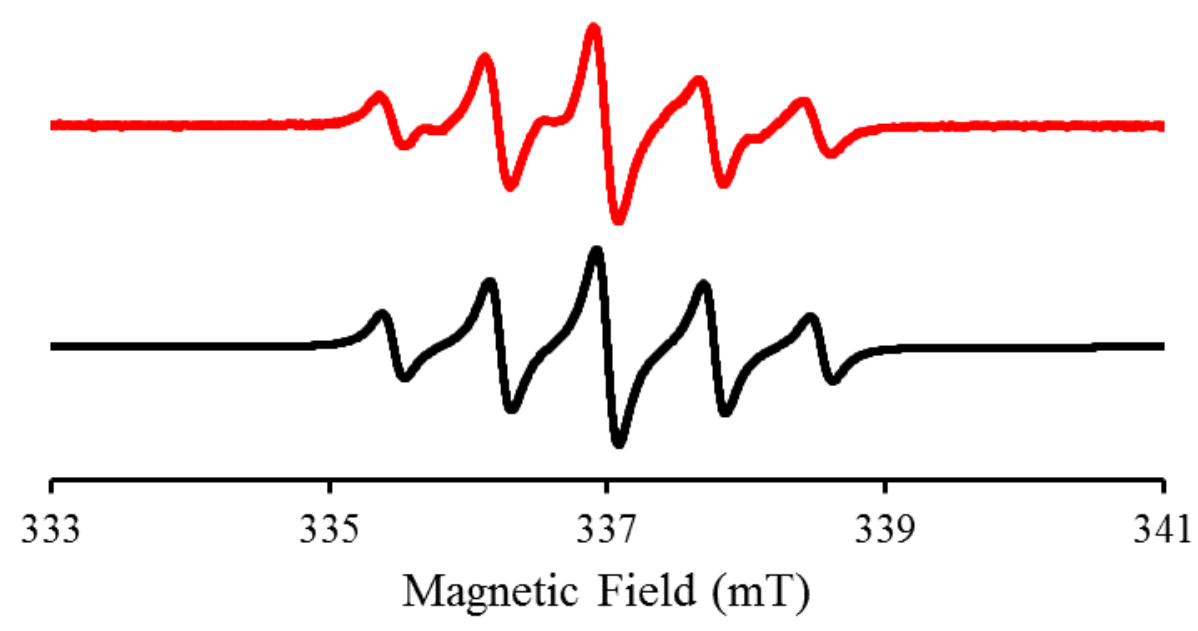

Figure S6. EPR spectrum (red) and simulated EPR spectrum (black) of radical functionalized AuNP. Parameters used for simulation: line width $=0.16 \mathrm{mT}, \mathrm{a}_{\mathrm{N} 1}=0.770 \mathrm{mT}$, and $\mathrm{g}=2.0068$. 

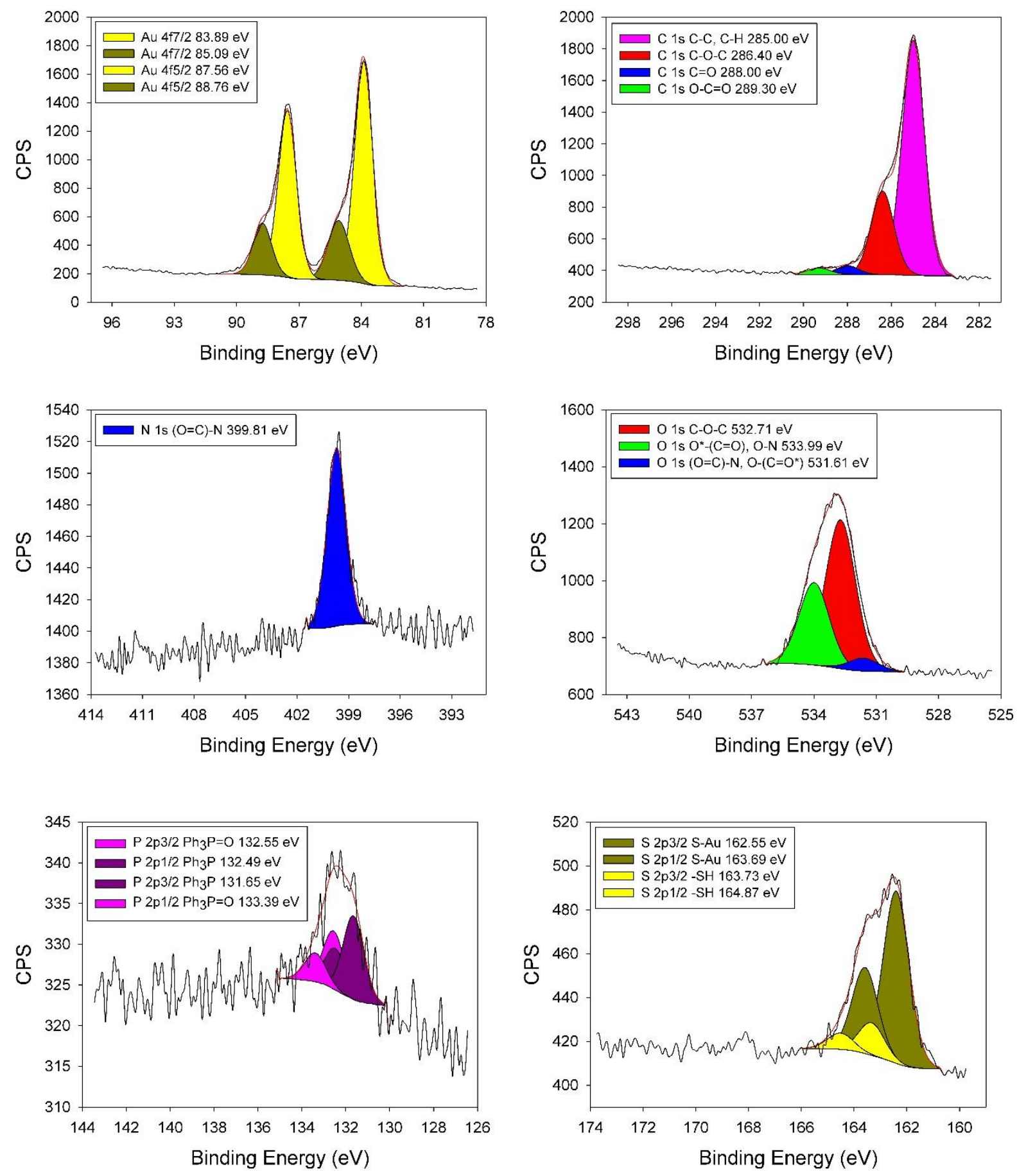

Figure S7. XPS characterization of radical-functionalized Staudinger-AuNP. 


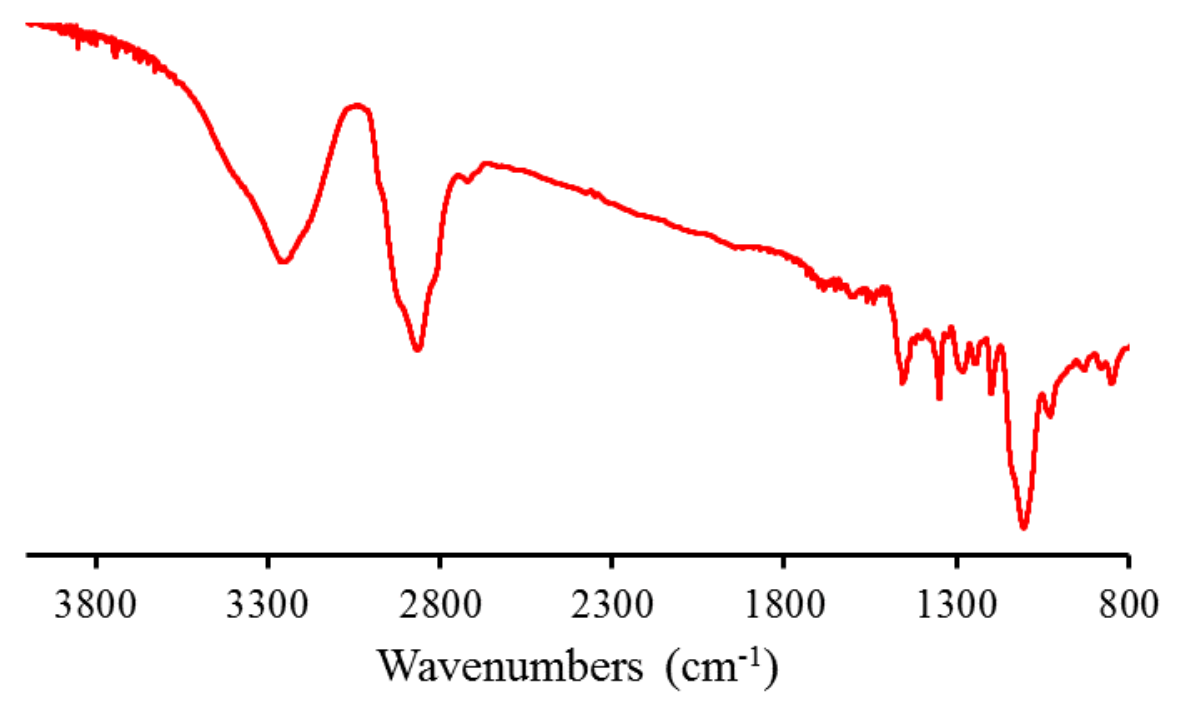

Figure S8. IR spectrum of control Staudinger-AuNP after washing procedure recorded as a film on $\mathrm{KBr}$ disk.

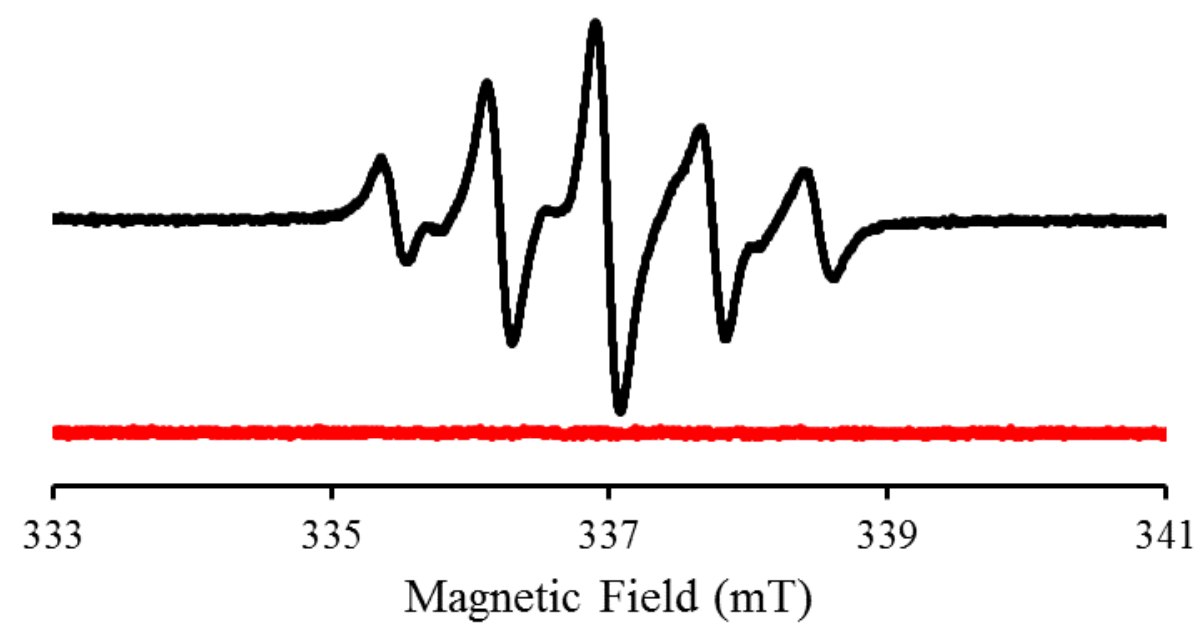

Figure S9. EPR spectrum of radical-functionalized Staudinger-AuNP (black) and control Staudinger-AuNP (red) after washing procedure in $\mathrm{CH}_{2} \mathrm{Cl}_{2}$. Both samples are at the same concentration $\left(3.3 \mathrm{mg} \mathrm{mL}^{-1}\right)$. 


\section{References}

1. Yilmaz, M. D., Bozdemir, O. A. and Akkaya, E. U., Org. Lett., 2006, 8, 2871-2873.

2. Shimono, S., Tamura, R., Ikuma, N., Takimoto, T., Kawame, N., Tamada, O., Sakai, N., Matsuura, H., and Yamauchi, J., J. Org. Chem., 2004, 69, 475-481.

3. Gobbo, P., Luo, W., Cho, S. J., Wang, X., Biesinger, M. C., Hudson, R. H. E., and Workentin, M. S., Org. Biomol. Chem., 2015, 13, 4605-4612.

4. Wang, C. C. Y., Seo, T. S., Li, Z., Ruparel, H. and Ju, J., Bioconjugate Chem., 2003, 14, $697-701$.

5. Bruker-Nonius, SAINT version 2012.12, 2012, Bruker-Nonius, Madison, WI 53711, USA

6. Bruker-Nonius, TWINABS version 2012.1, 2012, Bruker-Nonius, Madison, WI 53711, USA

7. Bruker-AXS, XS version 2012.10, 2012, Bruker-AXS, Madison, WI 53711, USA

8. Sheldrick, G. M., Acta Crystallogr. 2015, C71, 3-8. 